\title{
Evaluating the effect of coal mining subsidence on the agricultural soil quality using principal component analysis
}

\author{
Xiao-ming Guo ${ }^{1}$, Tong-qian Zhao ${ }^{1 *}$, Wen-ke Chang ${ }^{1}$, Chun-yan Xiao ${ }^{1}$, and Yu-xiao He ${ }^{1}$ \\ ${ }^{1}$ Henan Polytechnic University, Institute of Resources \& Environment, Jiaozuo 454003, China. \\ *Corresponding author (zhaotq@hpu.edu.cn).
}

Received: 12 January 2018; Accepted: 11 April 2018; doi:10.4067/S0718-58392018000200173

\begin{abstract}
Quantifying the effects of coal mining subsidence on soil quality is critical for developing sustainable strategies in the local agriculture. The objective of this study was to assess the effects of slope position because of coal mining on soil quality using principal component analysis. Soil samples were collected from five positions in the subsided farmland: Top slope position (1), upper slope position (2), middle slope position (3), lower slope position (4), and bottom position (5). Samples from an adjacent non-subsided farmland (CK) were used as a reference. For each soil sample, 21 different physical, chemical and biological attributes were investigated. The principal components analysis (PCA) identified the bulk density (BD), salinity, organic matter (OM) content, urease enzymatic activity (UA), actinomycete quantities (AQ), polyphenol oxidase enzymatic activity (POA) and phosphatase enzymatic activity (PA) as the most sensitive indicators in a minimum data set (MDS) to assess the soil quality. The soil quality index (SQI) was highest for positions 5 (1.220), 4 (1.203), CK (1.101), 1 (1.093), 3 (1.080), and 2 (1.044). Positions 5 and 4 had higher SQI values but lower crop yields than CK, which suggests that higher SQI does not represent higher production, and other soil quality indicators, which were not investigated in this study, had stronger effects on the crop productivity. Overall, the slope position because of coal mining subsidence strongly affected the soil quality and crop yields.
\end{abstract}

Key words: Coal mining subsidence, principal component analysis, slope position, soil quality index.

\section{INTRODUCTION}

Although renewable energy sources are attracting increasingly more attention, coal will continue to play an important role in satisfying the global demand for energy. The world production of coal is approximately $3.5 \times 10^{9} \mathrm{t} \mathrm{yr}^{-1}$, most of which is used to produce $38 \%$ of the world's electricity, and coal is an important energy resource for steel, cement and thermal power plants (Ram and Masto, 2010; Mukhopadhyay et al., 2016). China has the largest production and consumption of coal in the word, and approximately 95\% coal is obtained by underground mining (Bian et al., 2010; Wang et al., 2014). This mining method causes land subsidence, which destroys soil structure, changes its properties, and causes eco-environmental damages such as reduction in crop yields, restriction of vegetation growth, soil erosion, changes in topographic and hydrologic conditions, and loss of agricultural land and top soil (Meng et al., 2009; Yang et al., 2016; Shi et al., 2017; Wang et al., 2017). The effects of mining subsidence on agricultural land have been documented in many countries such as the USA (Darmody et al., 2014), Australia (Lechner et al., 2016), India (Tripathi et al., 2009), and China (Meng et al., 2012; Shang et al., 2016). These studies mainly focus on the damage of the surface and subsurface drainage, change of soil physico-chemical and biological characteristics, soil erosion and reduction of crop yields. 
Many studies concluded that topographic factors such as the slope position can significantly affect the crop productivity (Wezel et al., 2002; Grant et al., 2016), soil aggregation (Zou et al., 2015), soil water flow (Miller and Chanasyk, 2015), transformation of soil C and N (Tang et al., 2010; Hishi et al., 2014), and soil nutrient variability (Gou et al., 2015; Zhang et al., 2016). We hypothesize that the change in topographic conditions such as the slope position after mining subsidence can be hazardous and alter the soil properties and crop yields. However, until now, little is known about the effects of the slope position because of coal mining subsidence on soil quality.

Soil quality can be integrated from the soil physical, chemical and biological indicators and is defined as "the capacity of a soil to function, within land use and ecosystem boundaries, to sustain biological productivity, maintain environmental quality, and promote plant, animal and human health" (Liu et al., 2014). There are many methods to evaluate the soil quality, such as the soil quality index (SQI), which directly originates from the necessity of a science-based tool to measure soil quality and is perhaps the most common method because of its simplicity and quantitative flexibility (Armenise et al., 2013; Gong et al., 2015; Yu et al., 2018). Numerous studies concluded that the soil indicator values can be assimilated into a quantifiable SQI to show the soil quality using the principal component analysis (PCA) (Sharma et al., 2005; Mandal et al., 2008; Armenise et al., 2013; Gong et al., 2015; Mukhopadhyay et al., 2016; Nabiollahi et al., 2017).

The objective of the present study was to assess the soil quality based on 21 different physical, chemical and biological attributes, and calculate the SQI values to quantify the effects of mining subsidence on the agricultural soil quality, which varies with the slope position, using PCA.

Figure 1. Map of the studied area and locations of soil sampling sites.


MATERIALS AND METHODS

\section{Study area}

This study was conducted at the farmland of Hanwang coal mine (Figure 1), located in Macun district of Jiaozuo city $\left(35^{\circ} 10^{\prime}-35^{\circ} 21^{\prime} \mathrm{N}, 113^{\circ} 04^{\prime}-113^{\circ} 26^{\prime} \mathrm{E}\right)$, northwestern Henan Province, China. Jiaozuo City is well known for its energy, such as coal chemistry industries, and is a medium-sized city with a total area of $4071 \mathrm{~km}^{2}$ and a population of 3.6 million. 
It has a warm continental monsoon climate with an average annual temperature of $14{ }^{\circ} \mathrm{C}$, a mean annual rainfall of 658 $\mathrm{mm}$, and an annual evaporation of $2039 \mathrm{~mm}$. The production of raw coal in Jiaozuo city is approximately 5 million tons per year during the past decades. Consequently, this coal mining activity results in land subsided area of about $70 \mathrm{~km}^{2}$, soil quality damage and crop yields reduction. The effects on the sustainable development of agriculture for local inhabitant are rather adverse.

The specific study area was located in the farmland; this once-fertile farmland has produced low yields because of decades of coal mining subsidence. The altitude was approximately $115 \mathrm{~m}$, and the topography was changed from a flat land to a plate-shaped basin with the area of $2 \mathrm{~km}^{2}$. The angle of the slope is nearly $8^{\circ}$, and the largest subsided depth is approximately $12 \mathrm{~m}$. The seasonal crop was wheat (Triticum aestivum L.) or corn (Zea mays L.)

\section{Soil sampling}

The soil samples were collected from five positions in the subsided farmland: Top slope position (1), upper slope position (2), middle slope position (3), lower slope position (4), and bottom position (5) (Figure 1). At each position, three replicates of soil samples were taken from $0-20 \mathrm{~cm}$ depths, and each replicate was composed by mixing five random samples. Reference soil samples (CK) were collected from the nearby non-subsided farmland at Daiwang town. To analyze the quantities of bacteria, fungi and actinomycete in the soils, the samples were taken in ice boxes, transported to the laboratory, and stored at $4{ }^{\circ} \mathrm{C}$ until their analysis. For other physical, chemical and enzymatic analyses, a portion of the sample was air-dried for $7 \mathrm{~d}$, sieved with a 2 -mm screen, mixed and stored in sealed plastic bags.

\section{Soil analysis}

Contents of bulk density (BD), salinity, $\mathrm{pH}$, cation exchange capacity (CEC) and organic matter (OM) were determined using the metal-core sampler method, mass method, $\mathrm{pH}$ electrodes in soil/water (1:5) suspension, sodium acetate extraction method and dichromate oxidation technique, respectively (Lu, 2000). Contents of ammonium nitrogen (AN), nitrate nitrogen $(\mathrm{NN})$, total $\mathrm{N}(\mathrm{TN})$, available $\mathrm{P}(\mathrm{AP})$, total $\mathrm{P}(\mathrm{TP})$, available $\mathrm{K}(\mathrm{AK})$, and total $\mathrm{K}(\mathrm{TK})$ were measured with potassium chloride extraction, phenol disulfonic acid reaction, acid digestion, dicarbonate extraction, sodium hydroxide fusional, ammonium acetate extraction and sodium hydroxide fusional methods, respectively (Bao, 2000).

The quantities of bacteria (BQ), fungi (FQ) and actinomycete (AQ) were determined by serial dilution and colony counting (Lin, 2010). The enzymatic activities of urease (UA), sucrase (SA), phosphatase (PA), dehydrogenase (DA), catalase (CA), and polyphenol oxidase (POA) were measured using carbamide as the substrate, glucose as the substrate, potassium ferricyanide oxidation, reduction of 2,3,5-triphenyltetrazolium chloride (TTC), potassium permanganate as the titrant and pyrogallic acid as the substrate, respectively (Guan, 1986).

\section{Soil quality index (SQI)}

To determine the SQI values, three main steps were required: Selecting a minimum data set (MDS) of indicators that best represented soil function; assigning scores for the MDS indicators based on their performance of soil function; integrating the indicator scores into an index of soil quality.

To select an MDS, we can select few important indicators, which should be sensitive and well related to coal mining subsidence and depend on the PCA results. The principal components for a data set are defined as linear combinations of variables that account for the maximum variance in the set by describing the vectors of the closest fit to $\mathrm{n}$ observations in the p-dimensional space; the vectors are orthogonal to one another (Andrews et al., 2002). While there are many documented strategies for using PCA to select a subset from a large data set, the way used in this paper is similar to that described by Sharma et al. (2005). The principal components with higher eigenvalues and the variables with higher factor loading were assumed to be variables that better represented the system attributes. Thus, only the principal components with eigenvalues greater than 1 (Mandal et al., 2008; Mukhopadhyay et al., 2016) and those that explained at least 5\% of the variation in the data (Nabiollahi et al., 2017) were selected.

In each principal component, each variable is given a weight or factor loading that represents the contribution of that variable to the composition of the principal component. Only the highly weighted factors were retained for MDS, where the highly weighted factors were defined as those with absolute values within $10 \%$ of the highest factor loading. When more than one factor was reserved under a single principal component, Pearson's correlation coefficients were used 
to reduce redundancy among the highly weighted variables and determine whether the variables could be considered redundant and eliminated from the MDS (Andrews et al., 2002; Yu et al., 2018). The variable having the highest factor loading was considered for the MDS, while the significantly correlated variables were considered redundant and only one was considered for the MDS. The absolute values of the correlation coefficients were summed to choose variables within well-correlated groups for these variables. We assumed that the variable having the highest correlation sum since it is most generally related to the other variables and is considered to best represent the group, and the variable having the lowest correlation sum because of their implied relative independence was equally important. The remainder was eliminated from the data set. If the highly weighted variables were not correlated, each was considered equally important and retained in the MDS.

The SQI values were calculated for each observation using the following equation:

$$
S Q I=\sum_{i=1}^{n} W_{i} S_{i}
$$

where $S_{i}$ is the score for the variable in the MDS, and $W_{i}$ is the weighing factor derived from the PCA results.

The values of $\mathrm{S}$ for each observation in the MDS were transformed using a linear scoring method (Andrews et al., 2002; Marzaioli et al., 2010). The indicators were qualitatively grouped into "good" or "bad". A "good" indicator improved the soil quality, and a "bad" indicator deteriorated the soil quality. For a "more is better" indicator identified as "good", the observation with the highest value was assigned a score of 1 , and the scores for the remaining observations of this indicator were calculated as the ratio of their observation values over the highest observation value, and these scores are less than 1. For a "less is better" indicator identified as "bad", the observation with the smallest value was assigned a score of 1 , and the scores for the remaining observations of this indicator were calculated as the ratio of the lowest observation value over their observation values, and these scores are less than 1 . So we used "more is better" functions for soil nutrients and biological properties, and "less is better" functions for BD and salinity because of the damage effect on soil quality. Soil pH was evaluated using an "optimum" curve, but we applied it as a "less is better" indicator because the soil is weakly alkaline in the study area.

After the scores were assigned, the values of W were calculated from the PCA results using the methods of Sharma et al. (2005). Each principal component explained a certain amount (\%) of the variation in the total data set. This percentage, which is divided by the total percentage of variation explained by all principal components with eigenvectors larger than 1, provided the weighted factor for the variables that were selected under a given principal component. Having determined the values of $\mathrm{W}$ and $\mathrm{S}$, the SQI values for each soil in the different slope position were then calculated according to Equation [1]. Furthermore, the percent contribution of each final key indicator was also calculated.

\section{RESULTS}

\section{Physico-chemical characterization}

The soil physical and chemical characteristics in the study area are presented in Table 1. The contents of BD, salinity, $\mathrm{pH}$ values and CEC from position 1 to 5 were $1.50-1.69 \mathrm{~g} \mathrm{~cm}^{-3}, 0.22-1.12 \mathrm{~g} \mathrm{~kg}^{-1}, 8.37-8.64$ and $21.74-25.22 \mathrm{cmol} \mathrm{kg}^{-1}$, respectively. The contents were 14.10-16.17 $\mathrm{g} \mathrm{OM} \mathrm{kg}^{-1}, 0.84-1.60 \mathrm{~g} \mathrm{TN} \mathrm{kg}^{-1}, 0.57-0.84 \mathrm{mg} \mathrm{AN} \mathrm{kg}^{-1}, 6.96-8.65 \mathrm{mg} \mathrm{NN}$ $\mathrm{kg}^{-1}, 1.38-1.52 \mathrm{~g} \mathrm{TP} \mathrm{kg}^{-1}, 3.90-14.11 \mathrm{mg} \mathrm{AP} \mathrm{kg}^{-1}, 28.17-30.38 \mathrm{~g} \mathrm{TK} \mathrm{kg}^{-1}$, and 104.53-149.56 mg AK kg${ }^{-1}$. The soils in the mining subsided area contained lower average contents of salinity, CEC, OM, AN, NN, AK and TK but higher average contents of bulk density, $\mathrm{pH}$ values, $\mathrm{TN}, \mathrm{AP}$ and $\mathrm{TP}$ than the soils in the $\mathrm{CK}$ area.

The descriptive statistical analysis results showed a large difference between the minimum and maximum values of the soil properties, particular the soil salinity $\left(0.22-1.12 \mathrm{~g} \mathrm{~kg}^{-1}\right)$ and AP $\left(3.90-14.11 \mathrm{mg} \mathrm{kg}^{-1}\right)$. The soil BD, pH, CEC, OM, NN, TP, TK and AK contents had low CV values (<15\%), and soil AN and TN had moderate CV values (15\%-35\%). The soil salinity and AP contents had high CV values (>35\%). Overall, the descriptive statistics indicated high variability of some properties in the subsided area.

\section{Biological characterization}

The soil biological characteristics in the study area are shown in Table 2 . The quantities of bacteria, fungi and actinomycete from 1 to 5 were $9.31-17.69,0.08-0.16$, and $5.19-9.5910^{5} \mathrm{cfu}^{-1}$, respectively. The enzymatic activities of urease, sucrase, 
Table 1. The physical and chemical characters of soils in different sites of subsided area and controlled area.

\begin{tabular}{|c|c|c|c|c|c|c|c|c|c|c|c|c|c|}
\hline Layer & Sample site & $\mathrm{BD}$ & $\mathrm{pH}$ & Salinity & $\mathrm{OM}$ & $\mathrm{TN}$ & $\mathrm{TP}$ & TK & CEC & $\mathrm{AN}$ & $\mathrm{NN}$ & $\mathrm{AP}$ & $\mathrm{AK}$ \\
\hline $\mathrm{cm}$ & & $\mathrm{g} \mathrm{cm}^{-3}$ & & 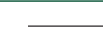 & 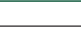 & $\mathrm{g} \mathrm{kg}^{-1}$ & & - & $\mathrm{cmol} \mathrm{kg}^{-1}$ & & $-\mathrm{m}$ & $\mathrm{kg}^{-1}$ & - \\
\hline \multirow[t]{6}{*}{$0-20$} & 1 & 1.62 & 8.48 & 1.12 & 16.09 & 0.98 & 1.38 & 28.63 & 21.74 & 0.74 & 8.13 & 5.93 & 107.96 \\
\hline & 2 & 1.69 & 8.61 & 0.91 & 14.79 & 0.84 & 1.48 & 28.54 & 22.17 & 0.80 & 8.65 & 7.58 & 104.53 \\
\hline & 3 & 1.67 & 8.62 & 0.85 & 16.17 & 1.60 & 1.52 & 28.48 & 23.48 & 0.64 & 7.92 & 14.11 & 116.34 \\
\hline & 4 & 1.51 & 8.64 & 0.34 & 14.10 & 1.12 & 1.45 & 28.17 & 25.22 & 0.84 & 6.96 & 3.90 & 122.87 \\
\hline & 5 & 1.50 & 8.37 & 0.22 & 16.17 & 1.12 & 1.46 & 30.38 & 23.91 & 0.57 & 7.65 & 5.95 & 149.56 \\
\hline & CK & 1.56 & 8.48 & 0.87 & 17.68 & 1.12 & 0.80 & 32.13 & 25.22 & 0.84 & 8.23 & 4.53 & 165.71 \\
\hline
\end{tabular}

BD: Bulk density, OM: organic matter, TN: total N, TP: total P, TK: total K, CEC: cation exchange capacity, AN: ammonium N, NN: nitrate N, AP: available P, AK: available $\mathrm{K}$.

(1) Top slope position, (2) upper slope position, (3) middle slope position, (4) lower slope position, (5) bottom position, (CK) adjacent control non-subsided farmland.

Table 2. The microbial characters of soils in different sites of subsided area and controlled area.

\begin{tabular}{|c|c|c|c|c|c|c|c|c|c|c|}
\hline Layer & $\underset{\text { site }}{\text { Sample }}$ & Bacteria & Fungi & Actinomycete & Urease & Sucrase & Phosphatase & Dehydrogenase & Catalase & $\begin{array}{c}\text { Polyphenol } \\
\text { oxidase }\end{array}$ \\
\hline \multicolumn{2}{|l|}{$\mathrm{cm}$} & \multicolumn{3}{|c|}{$-10^{5} \mathrm{~g}^{-1}$} & \multicolumn{2}{|c|}{$-\mathrm{mg} \mathrm{g}^{-1}$} & $\mathrm{mg} 100 \mathrm{~kg}^{-1}$ & $\mu \mathrm{L} \mathrm{g}^{-1}$ & $\mathrm{~mL} \mathrm{~g}^{-1}$ & $\mathrm{mg} \mathrm{g}^{-1}$ \\
\hline \multirow[t]{6}{*}{$0-20$} & 1 & 10.17 & 0.12 & 6.86 & 1.23 & 6.92 & 12.20 & 0.16 & 1.32 & 1.51 \\
\hline & 2 & 13.57 & 0.08 & 8.14 & 1.24 & 5.09 & 8.75 & 0.15 & 1.21 & 1.28 \\
\hline & 3 & 17.69 & 0.18 & 8.67 & 1.16 & 5.60 & 9.48 & 0.16 & 1.38 & 1.37 \\
\hline & 4 & 13.28 & 0.13 & 9.59 & 1.22 & 6.94 & 9.76 & 0.12 & 1.19 & 1.41 \\
\hline & 5 & 9.31 & 0.16 & 5.19 & 1.19 & 6.07 & 9.73 & 0.11 & 1.32 & 1.22 \\
\hline & $\mathrm{CK}$ & 19.30 & 0.10 & 7.13 & 1.24 & 6.59 & 8.90 & 0.13 & 1.39 & 1.43 \\
\hline
\end{tabular}

(1) Top slope position, (2) upper slope position, (3) middle slope position, (4) lower slope position, (5) bottom position, (CK) adjacent control non-subsided farmland.

phosphatase, dehydrogenase, catalase, and polyphenol oxidase were $1.16-1.24 \mathrm{mg} \mathrm{g}^{-1}, 5.09-6.94 \mathrm{mg} \mathrm{g}^{-1}, 8.75-12.20 \mathrm{mg}$ $100 \mathrm{~g}^{-1}, 0.11-0.16 \mu \mathrm{L} \mathrm{g}^{-1}, 1.19-1.38 \mathrm{~mL} \mathrm{~g}^{-1}$, and $1.22-1.51 \mathrm{mg} \mathrm{g}^{-1}$, respectively. The soils in the subsided area contained lower average quantities of bacteria and activities of urease, sucrase, catalase, and polyphenol oxidase but higher average quantities of fungi and actinomycete and activities of phosphatase and dehydrogenase than the soils in the CK area.

The descriptive statistical analysis results show a certain difference between the minimum and maximum values of the soil properties. The soil urease, sucrase, phosphatase, catalase, and polyphenol oxidase enzymatic activity showed low $\mathrm{CV}$ values $(<15 \%)$, and the soil bacteria, fungi and actinomycete quantities and dehydrogenase enzymatic activity had moderate CV values (15\%-35\%). Overall, the descriptive statistics showed fewer variability in soil biological properties compared with the physical and chemical properties.

\section{Principal component analysis}

Table 3 shows the primary five principal components (PCs). These components had eigenvalues greater than 1; together, they described $100 \%$ of the data variance. The significant loading factors (within 10\% of the variation of the absolute value of the highest factor loading in each PC) are highlighted in bold characters in Table 3. In PC1, BD was the greatest contributor to the PC as shown with the factor loading. In addition to BD, two variables (salinity and dehydrogenase activity) were considered significant. In PC2, three variables (OM, TP, and TK) were considered significant. In PC3, three variables (TN, fungi quantities, and urease activity) were considered significant. In PC4, two variables (pH values and actinomycete quantities) were considered significant. In PC5, three variables (sucrase activity, phosphatase activity, and polyphenol oxidase activity) were considered significant.

Pearson's correlation coefficients were derived for each significant variable from PC1 to PC5 (Table 4). In PC1, BD had the highest factor loading and was therefore retained for the MDS. Because the dehydrogenase activity in PC1 was significantly correlated with $\mathrm{BD}(\mathrm{R}=0.905, \mathrm{p}<0.05)$, it was excluded from the MDS. Because the salinity had the lowest correlation sum, it was included in the MDS. In PC2, OM had the highest factor loading and lowest correlation sum and was therefore retained for the MDS. Although TK had the highest correlation sum and was considered the best representative of the group, it was excluded from the MDS because it was significantly correlated with $\mathrm{OM}(\mathrm{R}=0.813, \mathrm{p}$ $<0.05)$. In PC3, the urease activity had the highest factor loading and highest correlation sum and was therefore retained 
Table 3. Results of the principal component analysis of the significant indicators of soil quality.

\begin{tabular}{|c|c|c|c|c|c|}
\hline & PC1 & PC2 & PC3 & PC4 & PC5 \\
\hline Eigenvalue & 5.122 & 5.083 & 4.547 & 3.483 & 2.766 \\
\hline Variance, $\%$ & 24.388 & 24.205 & 21.651 & 16.583 & 13.172 \\
\hline Cumulative & 24.388 & 48.593 & 70.245 & 86.828 & 100.000 \\
\hline \multicolumn{6}{|c|}{ Factor loading/eigenvector } \\
\hline Bulk density & $\underline{0.936}$ & -0.164 & 0.055 & 0.230 & -0.203 \\
\hline Salinity & $\underline{0.906}$ & 0.194 & -0.191 & 0.151 & 0.286 \\
\hline $\mathrm{pH}$ & 0.207 & -0.503 & 0.017 & $\underline{0.837}$ & -0.054 \\
\hline CEC & -0.795 & 0.395 & 0.065 & 0.454 & -0.028 \\
\hline Organic matter & 0.191 & $\underline{0.941}$ & 0.166 & -0.200 & 0.103 \\
\hline Ammonium $\mathrm{N}$ & -0.002 & 0.024 & -0.747 & 0.625 & 0.224 \\
\hline Nitrate $\mathrm{N}$ & 0.821 & 0.317 & -0.313 & -0.144 & -0.326 \\
\hline Total N & -0.033 & 0.192 & $\underline{0.916}$ & 0.348 & 0.043 \\
\hline Available P & 0.555 & -0.086 & 0.758 & 0.194 & -0.268 \\
\hline Total P & 0.089 & $\underline{-0.876}$ & 0.398 & -0.197 & -0.163 \\
\hline Available K & -0.563 & 0.814 & -0.019 & -0.092 & -0.111 \\
\hline Total K & -0.248 & $\underline{0.927}$ & -0.185 & -0.165 & -0.137 \\
\hline Bacteria & 0.174 & 0.562 & 0.118 & 0.788 & -0.140 \\
\hline Fungi & -0.236 & -0.061 & $\underline{0.957}$ & -0.129 & 0.088 \\
\hline Actinomycete & 0.047 & -0.439 & 0.007 & $\underline{0.893}$ & 0.092 \\
\hline Urease & 0.068 & 0.090 & $\underline{-0.981}$ & 0.042 & 0.149 \\
\hline Sucrase & -0.464 & 0.146 & -0.166 & -0.025 & $\underline{0.857}$ \\
\hline Phosphatase & 0.200 & -0.243 & 0.064 & -0.468 & $\underline{0.823}$ \\
\hline Dehydrogenase & $\underline{0.935}$ & -0.139 & 0.143 & 0.192 & 0.222 \\
\hline Catalase & 0.249 & 0.806 & 0.497 & -0.130 & 0.155 \\
\hline Polyphenol oxidase & 0.240 & 0.143 & -0.141 & 0.325 & $\underline{0.893}$ \\
\hline
\end{tabular}

PC: Principal component, CEC: cation exchange capacity.

Underlined factor loadings are considered highly weighted when within $10 \%$ of

variation of the absolute values of the highest factor loading in each PC.

for the MDS. Because TN and fungi quantities were significantly correlated with the phosphatase activity $(\mathrm{R}=-0.863$, $\mathrm{p}<$ $0.05 ; \mathrm{R}=-0.953, \mathrm{p}<0.01$ ), they were excluded from the MDS. In PC4, the actinomycete quantity had the highest factor loading and was therefore retained for the MDS. Because the $\mathrm{pH}$ value was significantly correlated with actinomycete $(\mathrm{R}=0.973, \mathrm{p}<0.01)$, it was excluded from the MDS. In PC5, the polyphenol oxidase activity had the highest factor loading and highest correlation sum and was therefore retained for the MDS. Because the phosphatase activity had the lowest correlation sum, it was included in the MDS. Hence, the final MDS consisted of BD, salinity, OM, urease activity, actinomycete quantities, polyphenol oxidase activity and phosphatase activity.

\section{Soil quality index}

The SQI for 1-5 and CK soils was calculated using Equation [1]. The S value in Equation [1] was obtained using a linear scoring method, and each variable had a score between 0 and 1. For BD and salinity, which are considered bad indicators, the 5 soil had the lowest value and was assigned a score of 1. For OM, which is considered a good indicator, the CK soil had the highest value and was assigned a score of 1 . For phosphatase and polyphenol oxidase, which are considered good, the 1 soil had the highest value and was assigned a score of 1 . For actinomycete, which is considered good, the 4 soil had the highest value and was assigned a score of 1 . For urease, which is considered good, both 2 and CK soils had the highest value and were assigned a score of 1 . After the score of 1 for the variable was assigned, the scores of BD, salinity, OM, urease activity, actinomycete quantities, polyphenol oxidase activity and phosphatase activity for each soil at different slope positions were derived using the method described in the soil quality index (SQI) section.

The W value in Equation [1], which was generated by the PCA, was obtained by dividing the percent of variation in the data set, which was interpreted by each PC that contributed the indicated variable(s), by the total percentage of variation, which was explained by all PCs with eigenvalues larger than 1. For BD, salinity, OM, urease activity (UA), actinomycete quantities (AQ), polyphenol oxidase activity (POA) and phosphatase activity (PA), the W values were $0.244,0.244$, $0.242,0.217,0.169,0.132$, and 0.132 , respectively. 
Table 4. Pearson's correlation coefficient and correlation sums for highly weighted variables with high factor loading under principal component.

\begin{tabular}{|c|c|c|c|}
\hline Variables & Bulk density & Salinity & Dehydrogenase \\
\hline \multicolumn{4}{|l|}{ PC1 variables } \\
\hline \multicolumn{4}{|l|}{ Pearson's correlation } \\
\hline Bulk density & 1 & 0.783 & $0.905^{*}$ \\
\hline Salinity & 0.783 & 1 & $0.886^{*}$ \\
\hline Dehydrogenase & $0.905^{*}$ & $0.886^{*}$ & 1 \\
\hline \multirow[t]{2}{*}{ Correlation sum } & 2.688 & 2.669 & 2.791 \\
\hline & Organic matter & Total P & Total K \\
\hline \multicolumn{4}{|l|}{ PC2 variables } \\
\hline \multicolumn{4}{|l|}{ Pearson's correlation } \\
\hline Organic matter & 1 & -0.719 & $0.813^{*}$ \\
\hline Total P & -0.719 & 1 & $-0.853^{*}$ \\
\hline Total K & $0.813^{*}$ & $-0.853 *$ & 1 \\
\hline \multirow[t]{2}{*}{ Correlation sum } & 2.532 & 2.572 & 2.666 \\
\hline & Total N & Fungi & Urease \\
\hline \multicolumn{4}{|l|}{ PC3 variables } \\
\hline \multicolumn{4}{|l|}{ Pearson's correlation } \\
\hline Total N & 1 & $0.832 *$ & $-0.863^{*}$ \\
\hline Fungi & $0.832^{*}$ & 1 & $-0.953 * *$ \\
\hline Urease & $-0.863^{*}$ & $-0.953 * *$ & 1 \\
\hline \multirow[t]{2}{*}{ Correlation sum } & 2.695 & 2.785 & 2.816 \\
\hline & $\mathrm{pH}$ & Actinomycete & \\
\hline \multicolumn{4}{|l|}{ PC4 variables } \\
\hline \multicolumn{4}{|l|}{ Pearson's correlation } \\
\hline $\mathrm{pH}$ & 1 & $0.973 * *$ & \\
\hline \multirow[t]{2}{*}{ Actinomycete } & $0.973 * *$ & 1 & \\
\hline & Sucrase & Phosphatase & Polyphenol oxidase \\
\hline \multicolumn{4}{|l|}{ PC5 variables } \\
\hline \multicolumn{4}{|l|}{ Pearson's correlation } \\
\hline Sucrase & 1 & 0.579 & 0.690 \\
\hline Phosphatase & 0.579 & 1 & 0.587 \\
\hline Polyphenol oxidase & 0.690 & 0.587 & 1 \\
\hline Correlation sum & 2.269 & 2.166 & 2.277 \\
\hline
\end{tabular}

PC: Principal component.

$*$,**Significant at the 0.05 and 0.01 probability levels, respectively.

Finally, the calculated SQI values were in the following order: $5(1.220)>4(1.203)>$ CK $(1.101)>1(1.093)>3$ $(1.080)>2$ (1.044). Figure 2 illustrates the relative contribution of each indicator to the SQI. The largest contributor was BD (21\%), followed by OM (19\%), UA (19\%), AQ (12\%), POA (11\%), PA (9\%), and salinity (9\%).

\section{DISCUSSION}

In this study, the influence of slope position because of mining subsidence on soil properties was evaluated, and the SQI was calculated to quantify the effects on soil quality using principal component analysis. Our results showed that the slope position has great effects on soil properties, which have been shown by others (Wezel et al., 2002; Tang et al., 2010; Zolfaghari et al., 2015; Zhang et al., 2016). Wezel et al. (2002) reported that soils at the lower mid slope contained 10\%$22 \%$ lower OM, N and P content compared to those at the upper mid slope positions. Zolfaghari et al. (2015) showed that the highest values of silt, OM content/clay and CEC/clay were found in the toe slope position. Unlike these studies, however, the distribution of soil properties along the slope did not have regularity in our study. The reason for this difference may be related to the slope formation process and anthropogenic activity. The studies of Wezel et al. (2002) and Zolfaghari et al. (2015) investigated the natural slope effects on soil properties in the hilly areas, whereas our study aimed at the anthropogenic slope in the mining subsidence. The slope in this study was gradually formed for decades in the mining and post-mining periods until it became stable, and its impact mechanism on soil properties is certainly different from the non-artificial slope. In addition, farmers preferred to cultivate more crops at the lower and bottom position than other sites to gain greater crop yields according to our field investigation. This preference of cropping activity 
Figure 2. Column graphs for soil quality index (SQI) for each slope position (1-5) and non-subsided farmland (CK) area. Each column depicts an individual position and scale represents the position score according to the principal components analysis. Higher score represents higher soil quality. In each column, seven attributes is as the most sensitive indicators in a minimum data set (MDS) to assess the soil quality.

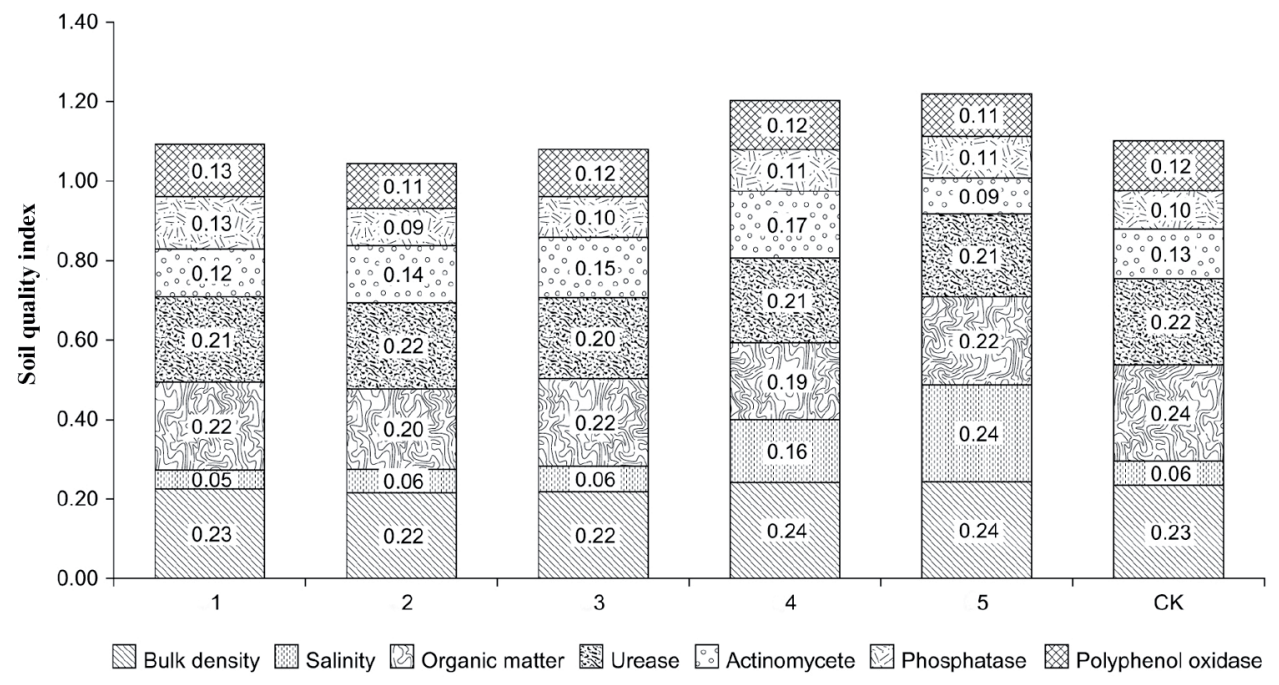

can also affect and intensify the spatial distribution of soil indicators in the subsided area, which results in complicated characteristics of spatial distribution.

In this study, the calculated SQI values were in the following order: $5(1.220)>4(1.203)>\mathrm{CK}(1.101)>1(1.093)>$ $3(1.080)>2(1.044)$, and the contributions of BD and OM to SQI were substantial (Figure 2). The SQI obviously varied with the slope position. It was mainly because the slope changed the spatial distribution of soil properties. Furthermore, more frequent and proper farming at the lower and bottom position may have positive influence on soil environment, which was likely to result in higher SQIs in the 5 and 4 than other sites. On average, BD and OM emerged as key indicators that contributed $21 \%$ and $19 \%$, respectively, to SQI. The BD is an important physical indicator and can reflect the soil texture and degree of soil compaction, which has often been used to evaluate the soil quality (Liu et al., 2014). Organic matter is an important part of soil and is fundamental for the soil fertility. As BD is a bad indicator and OM is a good indicator, the better soil quality could have lower content of BD and higher content of OM. Consequently, the soil 2 had the lowest SQI value because it had the highest BD and relatively low OM among all soil samples in the subsided area. In contrast, 5 had the highest SQI value because of the lowest BD and relatively high OM.

According to our field investigation, we found that the crop yields in the subsided farmland were much lower than those in the CK fields. Meanwhile, the SQI values of 5 and 4 were higher than those of CK, which suggests that higher SQI values can not represent higher crop production. This result is similar to the study of Armenise et al. (2013). Armenise et al. (2013) reported that there was no correlation between SQI and crop yield and suggested that other indicators that were not considered in his study were more influential on the crop productivity. We agreed with this view to interpret our study because we did not consider soil trace elements in this study, which can strongly affect the soil quality and crop yields. The findings of this study are useful for understanding the effects of slope position because of coal mining subsidence on soil properties and soil quality, and are critical for developing sustainable strategies to restore the productivity of farmland.

\section{CONCLUSIONS}

In this study, the soil quality index (SQI) values were calculated to quantify the influence of slope position because of coal mining subsidence on soil quality using principal component analysis. The SQI values irregularly varied with different slope positions. It was mainly because the slope changed the spatial distribution of soil properties, and preference of cropping activity by local farmers can also intensify the distribution. Bottom position and lower slope position had higher SQI values but lower crop production than the controlled area, which showed that higher SQI values can not 
represent higher crop production. It suggested that other soil quality indicators including trace elements, which were not investigated in this study, had a stronger effect on the crop productivity.

\section{ACKNOWLEDGEMENTS}

This study was financially supported by the National Natural Science Foundation of China (41371501, 41502241 and U1704241), and Science and Technology Research Project of Henan Province (172102310354).

\section{REFERENCES}

Andrews, S.S., Karlen, D.L., and Mitchell, J.P. 2002. A comparison of soil quality indexing methods for vegetable production systems in Northern California. Agriculture Ecosystems and Environment 90:25-45.

Armenise, E., Redmile-Gordon, M.A., Stellacci, A.M., Ciccarese, A., and Rubino, P. 2013. Developing a soil quality index to compare soil fitness for agricultural use under different managements in the Mediterranean environment. Soil and Tillage Research 130:91-98.

Bao, S.D. 2000. Soil agro-chemical analysis. $3^{\text {rd }}$ ed. China Agriculture Press, Beijing, China.

Bian, Z.F., Inyang, H.I., Daniels, J.L., Otto, F., and Struthers, S. 2010. Environmental issues from coal mining and their solutions. Mining Science and Technology 20:215-223.

Darmody, R.G., Bauer, R., Barkley, D., Clarke, S., and Hamilton, D. 2014. Agricultural impacts of longwall mine subsidence: The experience in Illinois, USA and Queensland, Australia. International Journal of Coal Science and Technology 1:207-212.

Gong, L., Ran, Q.Y., He, G.X., and Tiyip, T. 2015. A soil quality assessment under different land use types in Keriya river basin, Southern Xinjiang, China. Soil and Tillage Research 146:223-229.

Gou, Y., Chen, H., Wu, W., and Liu, H.B. 2015. Effects of slope position, aspect and cropping system on soil nutrient variability in hilly areas. Soil Research 53:338-34.

Grant, C.A., Moulin, A.P., and Tremblay, N. 2016. Nitrogen management effects on spring wheat yield and protein concentration vary with seeding date and slope position. Agronomy Journal 108:1246-1256.

Guan, S.Y. 1986. Soil enzyme and its research methods. China Agriculture Press, Beijing, China.

Hishi, T., Urakawa, R., Tashiro, N., Maeda, Y., and Shibata, H. 2014. Seasonality of factors controlling N mineralization rates among slope positions and aspects in cool-temperate deciduous natural forests and larch plantations. Biology and Fertility of Soils 50:343-356.

Lechner, A.M., Baumgartl, T., Matthew, P., and Glenn, V. 2016. The impact of underground longwall mining on prime agricultural land: a review and research agenda. Land Degradation and Development 27:1650-1663.

Lin, X.G. 2010. Principles and methods of soil microbial research. China Higher Education Press, Beijing, China.

Liu, Z.J., Zhou, W., Shen, J.B., Li, S.T., and Ai, C. 2014. Soil quality assessment of yellow clayey paddy soils with different productivity. Biology and Fertility of Soils 50:537-548.

Lu, R.K. 2000. Chemical analysis methods of agricultural soil. China Agricultural Science and Technology Press, Beijing, China.

Mandal, U.K., Warrington, D.N., Bhardwaj, A.K., Bar-Tal, A., Kautsky, L., Minz, D., et al. 2008. Evaluating impact of irrigation water quality on a calcareous clay soil using principal component analysis. Geoderma 144:189-197.

Marzaioli, R., D'Ascoli, R., De Pascale, R.A., and Rutigliano, F.A. 2010. Soil quality in a Mediterranean area of Southern Italy as related to different land use types. Applied Soil Ecology 44:205-212.

Meng, L., Feng, Q.Y., Wu, K., and Meng, Q.J. 2012. Quantitative evaluation of soil erosion of land subsided by coal mining using RUSLE. International Journal of Mining Science and Technology 22:7-11.

Meng, L., Feng, Q.Y., Zhou, L., Lu P., and Meng, Q.J. 2009. Environmental cumulative effects of coal underground mining. Procedia Earth and Planetary Science 1:1280-1284.

Miller, J.J., and Chanasyk, D.S. 2015. Unsaturated water flux at mid and lower slope positions within an inclined landscape of the Dark Brown soil zone in southern Alberta. Canadian Journal of Soil Science 95:27-36.

Mukhopadhyay, S., Masto, R.E., Yadav, A., George, J., Ram, L.C., and Shukla, S.P. 2016. Soil quality index for evaluation of reclaimed coal mine spoil. Science of the Total Environment 542:540-550.

Nabiollahi, K., Taghizadeh-Mehrjardi, R., Kerry, R., and Moradian, S. 2017. Assessment of soil quality indices for salt-affected agricultural land in Kurdistan Province, Iran. Ecological Indicators 83:482-494.

Ram, L.C., and Masto, R.E. 2010. An appraisal of the potential use of fly ash for reclaiming coal mine spoil. Journal of Environmental Management 91:603-617.

Shang, W.Q., Tang, Q., Zheng, L.G., and Cheng, H. 2016. Chemical forms of heavy metals in agricultural soils affected by coal mining in the Linhuan subsidence of Huaibei Coalfield, Anhui Province, China. Environmental Science and Pollution Research 23:23683-23693. 
Sharma, K.L., Mandal, U.K., Srinivas, K., Vittal, K.P.R., Mandal, B., Grace, J.K., et al. 2005. Long-term soil management effects on crop yields and soil quality in a dryland Alfisol. Soil and Tillage Research 83: 246-259.

Shi, P.L., Zhang, Y.X., Hu, Z.Q., Ma, K., Wang, H., and Chai, T.Y. 2017. The response of soil bacterial communities to mining subsidence in the west China aeolian sand area. Applied Soil Ecology 121:1-10.

Tang, X.Y., Liu, S.G., Liu, J.X., and Zhou, G.Y. 2010. Effects of vegetation restoration and slope position on soil aggregation and soil carbon accumulation on heavily eroded tropical land of Southern China. Journal of Soils and Sediments 10:505-513.

Tripathi, N., Singh, R.S., and Singh, J.S. 2009. Impact of post-mining subsidence on nitrogen transformation in southern tropical dry deciduous forest, India. Environmental Research 109:258-266.

Wang, W.F., Hao, W.D., Bian, Z.F., Lei, S.G., Wang, X.S., Sang, S.X., et al. 2014. Effect of coal mining activities on the environment of Tetraena mongolica in Wuhai, Inner Mongolia, China-A geochemical perspective. International Journal of Coal Geology 132:94-102.

Wang, Y.C., Bian, Z.F., Lei, S.G., and Zhang, Y. 2017. Investigating spatial and temporal variations of soil moisture content in an arid mining area using an improved thermal inertia model. Journal of Arid Land 9:712-726.

Wezel, A., Steinmüller, N., and Friederichsen, J.R. 2002. Slope position effects on soil fertility and crop productivity and implications for soil conservation in upland northwest Vietnam. Agriculture, Ecosystems and Environment 91:113-126.

Yang, D.J., Bian, Z.F., and Lei, S.G. 2016. Impact on soil physical qualities by the subsidence of coal mining: a case study in Western China. Environmental Earth Science 75:652.

Yu, P.J., Liu, S.W., Zhang, L., Li, Q., and Zhou, D.W. 2018. Selecting the minimum data set and quantitative soil quality indexing of alkaline soils under different land uses in northeastern China. Science of the Total Environment 616:564-571.

Zhang, S.L., Jiang, L.L., Liu, X.B., Zhang, X.Y., Fu, S.C, and Dai, L. 2016. Soil nutrient variance by slope position in a Mollisol farmland area of Northeast China. Chinese Geographical Science 26:508-517.

Zolfaghari, Z., Mosaddeghi, M.R., Ayoubi, S., and Kelishadi, H. 2015. Soil atterberg limits and consistency indices as influenced by land use and slope position in Western Iran. Journal of Mountain Science 12:1471-1483.

Zou, L.Q., Chen, F.S., Duncan, D.S., Fang, X.M., and Wang, H.M. 2015. Reforestation and slope-position effects on nitrogen, phosphorus pools, and carbon stability of various soil aggregates in a red soil hilly land of subtropical China. Canadian Journal of Forest Research 45:26-35. 